\title{
The potential impact of small-scale flywheel energy storage technology on Uganda's energy sector
}

\author{
Richard Okou \\ Adoniya Ben Sebitosi \\ Azeem Khan \\ Department of Electrical Engineering, University of Cape Town
}

Pragasen Pillay

Department of Electrical and Computer Engineering, Concordia University

\begin{abstract}
The energy crisis in Uganda has caused a sharp decline in the growth of the industry sector from $10.8 \%$ to $4.5 \%$ between $2004 / 5$ and $2005 / 6$. This crisis has escalated the power disruptions, which have had adverse effects on various sectors. While business owners have resorted to importation of fossil fuel generators that have increased the cost of production, others have resorted to battery energy storage systems to cater for short outages, which are limited in life span, depth of discharge, among others. These interventions have, thus, further increased the cost of goods and services. In addition, the rural populations using solar home systems incur high battery maintenance and replacement costs. In this paper an electromechanical flywheel battery is proposed as a better alternative in mitigating energy storage problems. It is found that by replacing the battery storage systems with the electromechanical flywheel battery, a saving of up to $35 \%$ on cost of energy can be made in the solar home systems and for the industry sector, the power disruptions could be reduced.
\end{abstract}

Keywords: flywheel, energy storage, cost of energy, life cost analysis

\section{Introduction}

Uganda's population stands at 27.2 million people, with $12 \%$ being urban based. Only $2 \%$ of rural areas and 5\% of the entire population in Uganda has access to electricity (UBOS 2002; Energy Policy 2002). These non-electrified areas are usually far from the grid, in mountainous areas, or not consid- ered economically viable. Of those connected to the grid, approximately $30 \%$ have frequent disruptions resulting from power instability and causing revenues losses in the different sectors of the economy.

The non-grid connected areas, mostly rural, are powered with solar home systems, whose sustainability is limited by the short life span of the battery storage. The most commonly used batteries in Uganda last only up to 3 years and it is estimated that probably US\$100 Million is spent on replacing them (MEMD, 2004). These batteries account for $30 \%$ of the initial cost of the components of the whole system (Bart, 1999).

The energy crisis has caused a decline in industrial growth from $10.8 \%$ in the financial year $2004 / 5$ to $4.5 \%$ in $2005 / 6$ with the manufacturing sector sharply falling from $13.5 \%$ to $-3.5 \%$ (Ezra, 2006/7). This crisis is projected to continue until the government's short, medium, and long-term plans come into effect. The sharp fall in economic growth is not only attributed to inadequate energy but also the power disruptions. In order to reduce this financial loss due to the energy crisis, business owners in various sectors have resorted to the importation and use of fossil-based fuel generators. These generator sets account for more than $60 \mathrm{MW}$, thus spending up to US\$19 million annually (MEMD, 2004). The use of fossil fuel generators has further pushed up the price of goods and services, leaving the ordinary rural masses even poorer (EPRC, 2006). In advanced process systems, where power disruptions cause serious losses, huge battery banks are used to handle the short-term power disruptions. However, these have shortcomings due to among others, short life spans, low depth of discharge, limited charge/discharge cycles and envi- 
ronmental concerns from disposal of wastes.

The electromechanical flywheel battery is an age-old technology that has seen recent revival and could subsequently evolve to address the above technical and environmental concerns.

This paper investigates the potential impacts of small-scale flywheel systems for use in the rural and urban areas in Uganda.

\section{Energy storage}

Energy storage systems are required to store electricity mainly when the demand and/or generation costs are low. In addition, energy storage is used when the intermittent energy sources such as wind and solar power are used to harness power.

The different energy storage technologies coexist as their characteristics make them attractive to different applications. In selecting an energy storage system, both the technical and economical characteristics should be explored. A methodology that includes most of the major characteristics of the technologies should be considered. The various types of storage technologies include: Chemical Batteries, Flywheels, Reversible fuel cells, Electromagnetic super-conductors, Compressed air, Supercapacitor and Pumped hydro storage.

\section{Flywheel technology}

The flywheel has been in existence for millennia and has since evolved from the potter's flywheel, to steel and subsequently to the more advanced composite carbon fibre. The origins and use of modern flywheel technology for mechanical energy storage can be traced to several hundred years ago and was further developed throughout the industrial revolution.

The latest advances in power electronics, strength of materials and high performance bearings have seen the flywheel exploited for various applications including attitude control in space crafts, pulsed power in military vehicles, frequency regulation and energy storage among others. Research continues in these applications to increase the efficiency and performance of the flywheel. The advantages associated with flywheels include: long life, environmentally friendly, high depth of discharge, large number of charge/discharge cycles, high energy density and fast response time among others. Flywheels are mainly considered for uninterrupted power supplies (UPS), vehicles, space and energy storage applications (Robert 2001; Andrei, series 6; Genta 1985; Sebitosi 2004; Bolund 2007).

\subsection{Small scale flywheel energy storage systems}

Flywheels are generally classified as low speed or high speed, whose base distinction is 10000 -rpm rotor speed. In this study small-scale flywheels are those that can store up-to $6 \mathrm{kWh}$. These systems are already commercially available and can be designed with high or low speed.

The amount of energy that a flywheel can store is given by (Genta, 1985):

$$
E=1 / 2 J \omega^{2}
$$

Where $\mathrm{J}$ is the moment of inertia and is dependent on the geometry of the flywheel rotor and $\omega$ is the angular velocity of the rotor.

The maximum velocity that the flywheel can be rotated at is limited by the density $\rho$, ultimate strength $\sigma$ and radius of the flywheel and is given by equation 2 .

$$
\sigma=\rho \omega^{2} r^{2}
$$

\section{Impact of energy storage on urban and rural economies}

Energy plays a crucial role in the overall development of a nation and observing the amount of electricity produced by the country can approximate the level of economic growth. Uganda produces $280 \mathrm{MW}$ as compared to South Africa's 40 000MW. Countries with more generating capacity are likely to reflect higher levels of standard of living (Khanh 2007; Harald 2005; Bhuiyan 2000; Igbinovia 2007).

Table 1: Generation capacity and GNP of selected countries Source: EIA, US

\begin{tabular}{lcc}
\hline Country & $\begin{array}{c}\text { Generation capacity } \\
\text { (Billion } k W h)\end{array}$ & $\begin{array}{c}\text { GNP per } \\
\text { capita }\end{array}$ \\
\hline South Africa & 228.33 & 4959 \\
\hline Egypt & 102.45 & 1255 \\
\hline Algeria & 31.91 & 2727 \\
\hline Nigeria & 22.53 & 564 \\
\hline Zambia & 8.85 & 486 \\
\hline Uganda & 1.98 & 276 \\
\hline
\end{tabular}

\subsection{Urban power disruptions}

Poor power quality can eliminate the thin advantage that a company has over its competitors. Of 563 firms surveyed in Uganda in 2006 by an enterprise survey (307 from the manufacturing sector), $63.9 \%$ found power interruptions to be the major hindrance to business, $60.5 \%, 69.3 \%$ and $76 \%$ of small, medium and large respectively. In addition, losses from interruption in electricity supply as a percentage of sales were about $10 \%$ from $5 \%$ in 2003 (Enterprise, 2006).

Electricity disruptions increase costs, disrupt production, and lower revenue. 


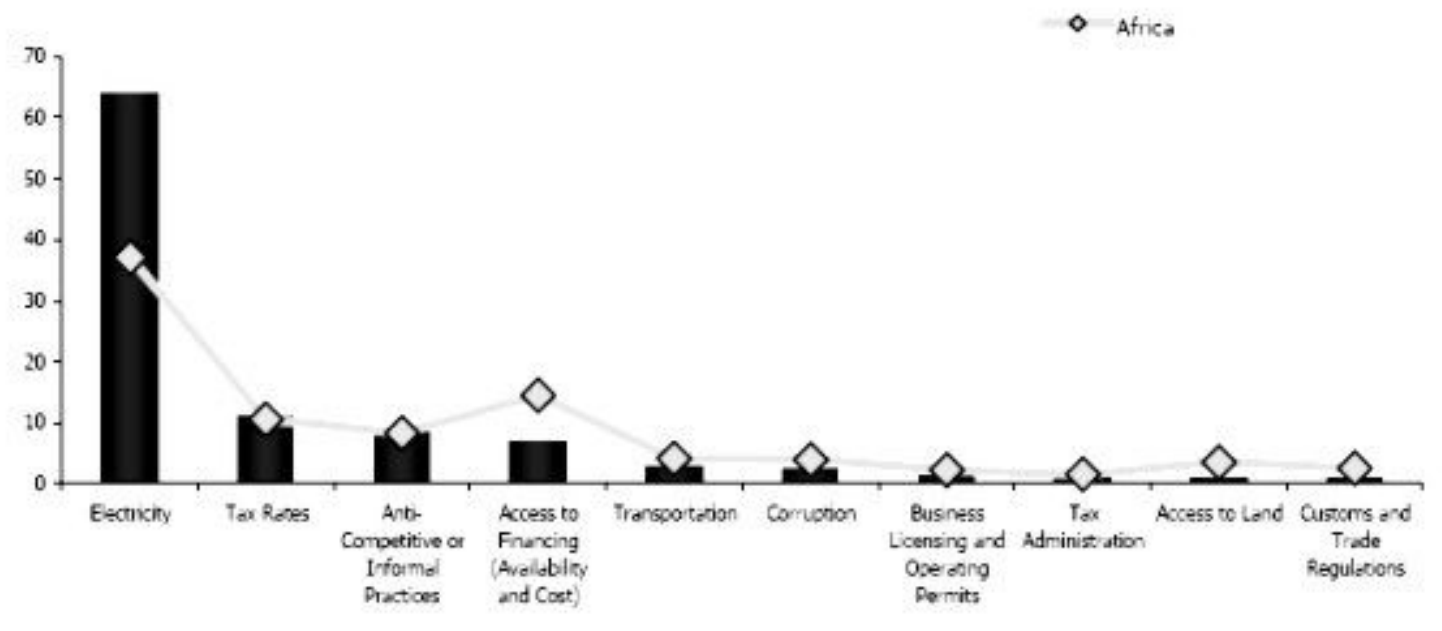

Percent of Firms Identifying the Problem as the Main Obstacle

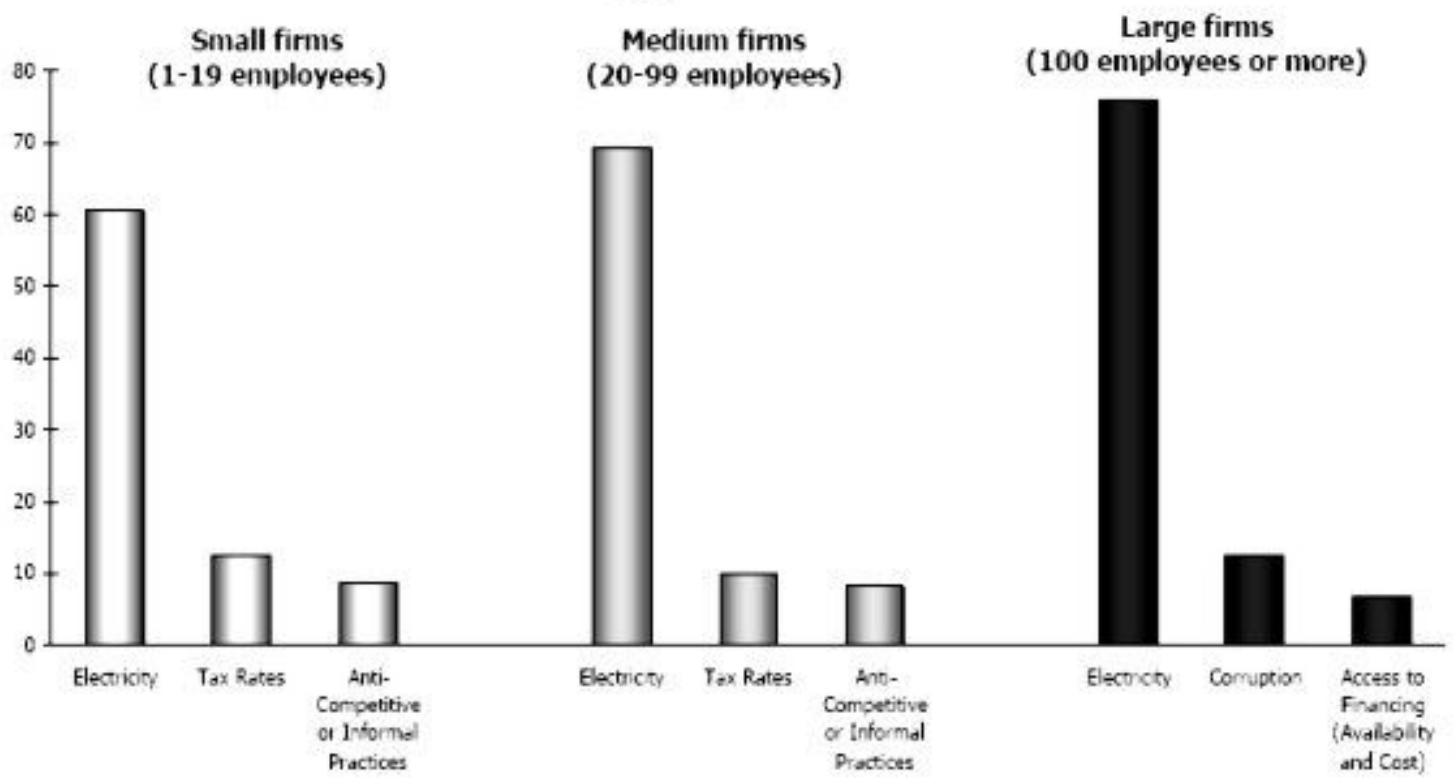

Figure 1: Effect of electricity on business

Source: Enterprise Surveys, Uganda profile, 2006

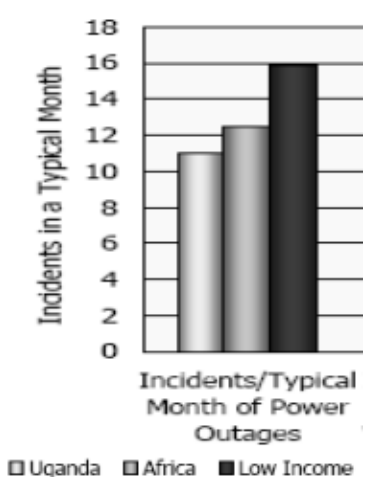

Figure 2: Monthly outages

Source: Enterprise surveys, Uganda profile, 2006
An independent survey done in Uganda revealed that the most common sag event lasted 15 -20 cycles, with $80 \%$ remaining voltage, and this accounted for $57 \%$ of the total faults (Mweru, 2007).

These disruptions culminate into loss of revenue hence decline in industrial growth as mentioned earlier. Short interruptions of less than 1 second can be devastating to equipment and the smooth operation of the industry. These require energy storage systems to abate the problem.

The most commonly used energy storage systems are battery banks that take up the sensitive 
load for short periods of time and when the interruptions last longer than anticipated, a fossil fuel operated generator comes online. The problems associated with chemical batteries as highlighted earlier are: limited charge/discharge cycles, depth of discharge, operating temperatures, response time, toxic disposal, high replacement costs and short life spans among others (Hall, 2000).

For such applications, the response time of the energy systems is vital, and research has shown that faults of less than 17 cycles cannot be trapped by battery storage. On the other hand, the electromechanical flywheel battery can be used to arrest such problems, reducing the revenue losses to a bare minimum.

In a case study (Roger, 2003) of an extruder plant, voltage sags in one extruder line stopped production 30 times every year, and resulting in a down time cost to the company of USD \$15 000 annually. A flywheel battery system was connected to the plant and this was able to capture the 17cycle sag. Plans are under way to improve the power factor of a second extruder line which would bring the total savings to USD $\$ 51000$. With the cost of the flywheel being USD $\$ 92000$ including maintenance and installation, the payback period was found to be less than two years.

\subsection{Rural electrification enhancement}

The government of Uganda developed a rural electrification strategy and plan 2001 to 2010 and this was to increase electricity access in rural areas from $1 \%$ to $10 \%$ between 2001 and 2010 (RESP, 2001). The strategies outlined in the plan include:

- Grid extension

- Mini grids

- Stand alone (PV, Pico hydro)

- Grid-embedded renewable energy generation plants

Most rural areas in Uganda are sparsely populated making grid extension a very costly venture. The alternative sources used include solar PV and hydropower systems. This rural electrification is mainly focused on electrification of rural households, health centres, community services (e.g. water pumping, schools, etc), and telecommunications.

Solar energy is abundantly available throughout Uganda with good average insulation of about 4$5 \mathrm{kWh} / \mathrm{m}^{2} /$ day. It is estimated that there are 66355 PV solar systems, with an estimated 5.31 MW annual power (URA 2001; MEMD 2007)

The number of solar systems is increasing steadily and hence there is dire need to enhance the energy storage systems used to better the life cycle of the whole system. The current storage system used is a string of batteries and this paper proposes the replacement of the batteries with small-scale flywheels.

\section{Methodology}

The life cycle cost analysis considered in this study is to compare the levelized cost per unit of energy for the entire evaluation period rather than use the capital costs or operating costs for the different systems. This is envisaged to give a more realistic cost of energy evaluation.

A life cycle cost analysis is shown below between a flywheel storage system and a battery storage system used in a 300 Wh solar home system. This was done using an analytical method (Bhuiyan, 2000) and a free simulation program HOMER, developed by the national renewable energy laboratory (NREL, 2007).

\section{Method 1}

An analytical method was used to determine the life cycle costs in this section (Bolund, 2007).

$$
L C=\frac{C+M+R}{E}
$$

Where:

C - Capital costs including the installation and equipment purchase before system operation

M - Annual operation and maintenance costs

$\mathrm{R}$ - Replacement costs

E - Annual energy output received over $\mathrm{N}$ years

$$
\begin{aligned}
& M=A M C \times\left(\frac{\left(1+e_{o}\right)}{\left(d-e_{o}\right)}\right)\left[1-\left(\frac{\left(1+e_{o}\right)}{1+d}\right)^{N}\right] \\
& R=\sum_{i=1}^{v}\left[\cos t\left(\frac{1+e_{o}}{1+d}\right)^{r y}\right] \\
& E=A\left[\frac{1-(1+d)^{-N}}{d}\right]
\end{aligned}
$$

SolarPV system characteristics:

Energy: 300Wh/day

Peak power: $60 \mathrm{~W}$

Solar Panel size:80 W (5-hrs for central Uganda and East, $20 \%$ in cloudy days and system losses of $80 \mathrm{~W})$

Charge controller: 10 amps

Battery depth of discharge: $50 \%$

Battery size: 50Ah

Battery life span: 3 years

Flywheel life span: 20 years

General economic indicators (BOU, 2007):

Life span: 20 years

Discount rate: $13.48 \%$

Fuel inflation: $16.5 \%$

General inflation: $6.4 \%$

Total energy: 20 years x 365 days/year x 300Wh

$=2190 \mathrm{kWh} / 20$ years 
Using lead-acid batteries as an energy storage system:

i) Capital costs:

\begin{tabular}{lc} 
Item & Capital costs (\$ USD) \\
\hline Solar panel, 80W & 500 \\
\hline Charge controller,10A & 70 \\
\hline Battery, 50Ah & 115 \\
\hline Panel frame & 23 \\
\hline Cabling and installation & 100 \\
\hline Total & 808 \\
\hline
\end{tabular}

ii) Recurring costs

This is $2 \%$ of the capital cost and taking inflation and the discount rate into consideration, this was found to be \$USD 175.9

iii) Non-recurring costs

These are mainly component replacement costs: Item Replacement Replacement LCC

\begin{tabular}{lccc} 
& cost & year \\
\hline Batteries & 1,150 & 2 & 2160.98 \\
\hline Charge controller & 140 & 10 & 213.5108 \\
\hline Total & & & 2374.49 \\
\hline
\end{tabular}

iv) Using equation 4, the life cycle cost is USD 1.53

Using a flywheel as energy storage system

The battery system was replaced with a flywheel and using the same approach, the LCC was found to be \$USD 0.99. In addition to the data given, the maintenance costs of the flywheel system were taken to be $1 \%$ of the capital costs as compared to the battery system.

\section{Method 2:}

A simulation program, HOMER (NREL, 2007) was used to validate the results. The levelized cost of energy for the system using batteries as energy storage was found to be \$USD 1.611 and for the flywheel was \$USD 1.368.

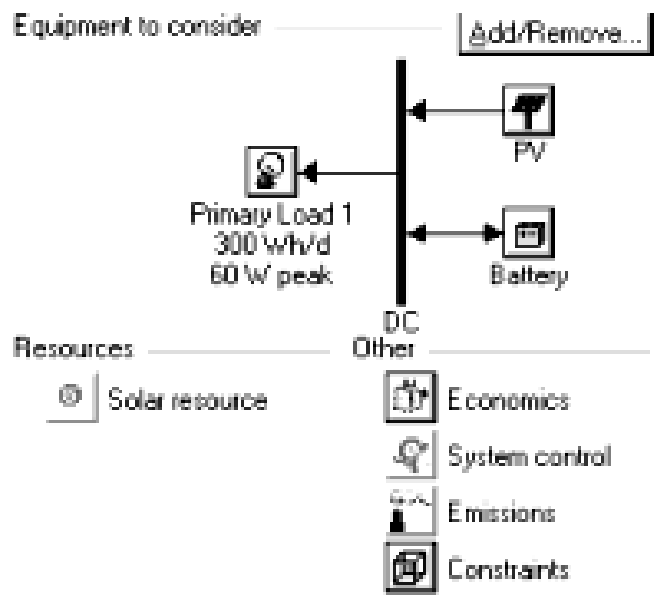

Figure 3: Design schematic
The results screens of the HOMER simulations for the different energy storage systems are shown in Figures 4 and 5 below.

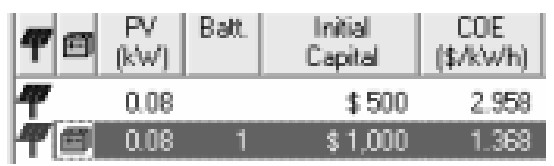

Figure 4: Cost of energy for flywheel system (battery represents the flywheel)

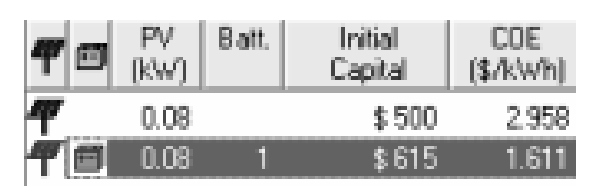

Figure 5: Cost of energy for battery system

The toxic wastes from the batteries were not included in simulations.

\section{Conclusion}

A comparison has been done between the life cycle costs of the traditional lead acid battery storage system and a proposed y that would have been used on maintenance and replacement on the traditional lead acid batteries can noelectromechanical flywheel battery for a rural energy storage application, using two different models. It has been shown that the flywheel is more cost effective in the long run than the traditional lead battery.

Drawing from the above, it is evident that smallscale flywheel energy storage has the potential to improve power disruption and rural electrification problems in Uganda. The savings made on the enhanced power quality can bridge the competitiveness that local companies need over foreign companies. The down time of companies can also be reduced significantly. The use of electromechanical flywheel battery storage would mitigate the environmental problems associated with lead acid battery disposal. These systems can also be used in health centres; schools and telecommunications base stations as they fall within the power/energy range.

Integrating the flywheel system into solar home systems would mean making a saving of $35 \%$ per $\mathrm{kWh}$ with rural systems. More robust and cheap systems are being designed, tested to improve the performance, durability and viability of the flywheel systems.

In addition, monew be used for more productive activities like education, health, food and other basic household needs hence addressing the Millennium Development Goals, which includes eradication of poverty among others.

Research is ongoing at the University of Cape Town to develop a low cost flywheel specifically for rural areas. 


\section{References}

Bhuiyan, MMH, M. Ali Asgar, R.K. Mazumder, M. Hussain, 2000. Economic Evaluation of a Standalone Residential Photovoltaic Power System in Bangladesh, Renewable energy, Vol. 21, pp. 403410.

Bolund, B, H. Bernhoff, M. Leijon, 2007. Flywheel Energy and Power Storage Systems. Renewable and Sustainable Energy Reviews, Vol. 11, pp. 235-258.

Economic Policy Research Centre, EPRC, The Ugandan Economy today, Vol. 11, No. 1, January - March 2006.

Energy Policy, Uganda, 2002.

Enterprise surveys, country profile Uganda, 2006.

Genta, G, 1985. Kinetic Energy Storage, Theory and Practice of Advanced Flywheel Systems, Butterworth.

Hall, CD, 2000. Integrated Spacecraft Power and Attitude Control Systems Using Flywheels, Air Force Institute of Technology.

Igbinovia, SO, P.E. Orukpe, 2007. Rural Electrification: the Propelling Force for Rural Development of Edo state, Nigeria, Journal of Energy in Southern Africa, Vol. 18, No. 3, August

Investing in Uganda's Energy sector, MEMD 2004.

Lawrence, RG, Kim L Craven, Gary D Nichols. 2003. Flywheel UPS, An Economical Energy Storage Device that Bridges the Gap Caused by Voltage Sags and Temporary Voltage Loss, IEEE Industry Applications Magazine, May/June 2003.

Ministry of Energy and Mineral Development, Uganda 2007.

Mweru, M, 2007. Uganda Electricity Distribution Company Limited.

Nguyen, K Q, 2007. Alternatives to Grid Extension for Rural Electrification, Decentralized Renewable Energy Technologies in Vietnam, Energy Policy, Vol. 35, pp. 2579-2589.

Rural Electrification Strategy and Plan, RESP, Uganda February 2001.

Sebitosi, A B , 2004. Application of Advances in Automotive Technologies to Electrification in Rural Sub-Saharan Africa, PhD thesis, 2004.

Suruma, E. 2007.Budget Speech, The Republic of Uganda, financial year 2006/07.

Ter-Gazarian, A. Energy Storage for Power Systems, IEE Energy series 6.

Uganda Bureau of Statistics 2002, Uganda Population and Housing Census, UBOS 2002.

Van Campen, B, Daniele Guidi, Gustavo Best. Impact of Solar Photovoltaic systems on rural development, FAO Study for Rural Electrification in the 21st Century, 17th Latin American Conference on Rural Electrification, Recife, Brazil, 7 - 11 November 1999.

Wesibach, R, George G Karady, Richard G Farmer, A Combined Uninterruptible Power Supply and Dynamic Voltage Compensator Using a Flywheel Energy Storage System, IEEE transactions on power delivery, Vol. 16, No. 2, April 2001.

Winkler, H, 2005. Renewable Energy Policy in South Africa: Policy Options for Renewable Electricity, Energy Policy, Vol. 33, 27-38 